\title{
Comunicação
}

[Communication]

\section{Níveis séricos da gama-glutamiltransferase em cães com e sem infecção natural por Leishmania (Leishmania) chagasi}

\author{
[Serum levels of gamma-glutamyl transferase in dogs naturally infected or not by \\ Leishmania (Leishmania) Chagasi] \\ I.F. Vidal ${ }^{1}$, I.V. Martins ${ }^{1}$, R.A. Lira ${ }^{2}$, M.N. Teixeira ${ }^{3}$, M.A.G. Faustino ${ }^{3}$, L.C. Alves ${ }^{3}$ \\ ${ }^{1}$ Aluna de pós-graduação - UFRPE - Recife, PE \\ ${ }^{2}$ Centro de Pesquisas Ageu Magalhães - FIOCRUZ - Recife, PE \\ ${ }^{3}$ Universidade Federal Rural de Pernambuco - Recife, PE
}

$\mathrm{Na}$ leishmaniose visceral canina (LVC), as alterações hepáticas estão associadas à evolução da doença, em função da multiplicação das formas amastigotas nos macrófagos (Tryphonas et al., 1977; Tafuri et al., 1996). Em geral, a hepatite crônica observada em animais com LVC é caracterizada por infiltrado linfoistioplasmocitário periportal (Ferrer, 1992), com proliferação fibroblástica, hipertrofia e hiperplasia das células de Kupffer (Hag, 1994).

Assim, a estase biliar intra-hepática tem sido observada pelo acúmulo de bilirrubina nos ductos e canalículos biliares em animais com LVC, especialmente quando o processo inflamatório e a fibrose acometem o parênquima hepático de modo considerável (Luvizotto, 2006).

Entre os testes de função hepática realizados no diagnóstico de hepatopatias, a determinação dos níveis séricos de fosfatase alcalina (FA), alanina transaminase (ALT), aspartato transaminase (AST) e gama-glutamil transferase (gama-GT) tem sido relatada como marcadora das desordens hepatobiliares (Sutherland, 1989; Dial, 1995). Apesar de a enzima gama-GT ter sua maior concentração no tecido renal e pancreático (Keller, 1981), sua importância clínica está ligada no diagnóstico da colestase (Sutherland, 1989; Dial, 1995) e de lesões hepáticas de caráter inflamatórias e tóxicas (Valladares et al., 1997).

Recebido em 7 de agosto de 2008

Aceito em 25 de maio de 2009

E-mail: ivanafv@yahoo.com.br
Contudo, pouco tem sido relatado sobre a utilização da gama-GT como método auxiliar no diagnóstico da LVC. Este trabalho teve o objetivo de avaliar os níveis séricos da gamaglutamil transferase em cães com infecção natural por Leishmania (Leishmania) chagasi.

Foram avaliados 55 cães adultos, distribuídos em dois grupos. O grupo infectado (GI) foi constituído por 41 animais com suspeita clínica de leishmaniose visceral, de raças e idades variadas, de ambos os sexos, com exames parasitológico positivo para Leishmania (Leishmania) chagasi, e sorológico pelo ELISA ${ }^{1}$, procedentes da região metropolitana de Recife. O grupo-controle (GC) foi composto por 14 animais sem sinais clínicos da infecção e com exames parasitológico e sorológico negativos para calazar canino, procedentes do Centro de Pesquisa Gonçalo Muniz, Salvador-BA. Os animais foram escolhidos por amostragem não probabilística por conveniência (Costa Neto, 2002).

De cada um dos animais foram colhidos, aproximadamente, $5 \mathrm{~mL}$ de sangue por venopunção cefálica, com seringa ${ }^{2}$ e agulha descartaveis. Ato contínuo, o material foi transferido para tubos estéreis e o soro resultante foi acondicionado em tubos de polipropileno e armazenado em freezer $\mathrm{a}-20^{\circ} \mathrm{C}$ até a realização da prova bioquímica.

\footnotetext{
${ }^{1}$ Kit para diagnóstico do Calazar Canino - GioCRuz - Bio Manguinhos, Rio de Janeiro, Brasil.

${ }^{2}$ Seringa descartáveis Becton Dickson - Curitiba, Brasil.
} 
Todos os animais foram submetidos à determinação sérica de gama-GT, por meio do método cinético com emprego de kits comerciais $^{3}$, de acordo com a instrução do fabricante, com leitura em espectofotômetro com absorbância de 405 nanômetros. Para comparação dos resultados de gama GT obtidos na prova bioquímica, foi utilizado o valor de referência de 1 a 10U/L (Shull e Hornbuckle, 1979; Willis et al., 1989). Para análise estatística dos resultados entre o GI e GC, empregaram-se os testes qui-quadrado e MannWhitney a 5\% de probabilidade (Campos, 1979).

Não foi observada diferença estatística entre os grupos quanto à determinação sérica de gama-GT. $\mathrm{O}$ resultado da prova bioquímica revelou altos níveis da gama-GT em apenas sete $(17,7 \%)$ dos animais do GI. Segundo Mattos et al. (2004), cães soropositivos apresentam valores bioquímicos séricos médios ligeiramente superiores aos dos cães soronegativos.

Os valores da média, mediana, P25 e P75 da gamaGT no GI foram considerados normais (Tab. 1). Nos animais do GI com elevado nível de gama GT, $42,8 \%(3 / 7)$ apresentavam valores de gama-GT duas a três vezes maior que o limite superior referencial utilizada para a espécie canina, o que é indicativo da doença hepática (Willis et al., 1989; Dial, 1995). Contudo, deve ser levado em consideração que o aumento é um indicador de doença hepatobiliar, e pode estar relacionado ao quadro de colestase em cães (Sutherland, 1989; Dial, 1995).

A gama-GT está presente no fígado assim como em outros órgãos, particularmente pâncreas e rins (Keller, 1981). A sua elevação pode ser relacionada à presença falha hepatobiliar observada em animais com LVC (Valladares et al., 1997).

Observou-se que $100 \%$ dos animais do GC e $82,9 \%$ GI apresentaram níveis basais compatíveis com a idade (1-10U/L), todavia, $17,7 \%$ do GI apresentaram alterações na atividade plasmática da enzima que excediam os valores de referência para faixa etária. Segundo Keller (1981), cães adultos saudáveis apresentam baixa concentração dessa enzima no soro, e a elevação significativa no nível de gama-GT ocorre particularmente em filhotes. Este achado confirma o grau de severidade do comprometimento hepático desses animais, considerando que o valor da GGT é um sinalizador das desordens hepatobiliares (Braun, 1983).

Tabela 1. Mediana, média, percentis (P25; P75) e valores máximo e mínimo da gama-GT (U/L) em cães naturalmente infectados e não-infectados por Leishmania chagasi

\begin{tabular}{lcccccc}
\hline & Mediana & Média & V. max. & V. min. & P 25 & P 75 \\
\hline Infectado & 5,3 & 7,37 & 35,52 & 1,41 & 5,3 & 7,77 \\
Não-infectado & 4,24 & 5,18 & 9,89 & 2,82 & 3,53 & 6 \\
\hline
\end{tabular}

Quanto aos sinais clínicos nos animais do GI com elevado nível sérico da gama-GT, observou-se perda de peso em dois cães $(28,6 \%)$ e presença de vômitos em apenas um $(14,3 \%)$, sendo este último sinal menos comumente observado (Mattos et al., 2004). Segundo Noli (1999), a perda de peso e a presença de vômitos são manifestações clínicas da LVC, provocadas pela hepatite crônica que ocorre pela multiplicação do parasita nos macrófagos hepáticos. Desse modo, conclui-se que a determinação da gama-GT não constitui um método auxiliar no diagnóstico de leishmaniose visceral canina em razão da baixa sensibilidade do teste.

Palavras-chave: cão, enzima, função hepática, calazar canino

\section{ABSTRACT}

The serum levels of Gamma-GT in dogs naturally infected by Leishmania (Leishmania) chagasi were evaluated. Two groups of animals were used: the first with 41 naturally infect dogs and the second with 14 uninfect animals. The results showed $17.1 \%$ (7/41) dogs presented high levels of gamma-GT, but no difference between groups was observed. So, the serum level of gamma-GT is not a tool for diagnosis of visceral leishmaniasis in dogs

Keywords: dog, enzyme, liver function, kala-azar

\footnotetext{
${ }^{3}$ Kit/Gama-gt - Katal Biotecnologia Ind. Com. - Belo Horizonte, Brasil.
} 


\section{REFERÊNCIAS BIBLIOGRÁFICAS}

BRAUN, J.P.; BERNARD, P.; BURGAT, V. et al. Gamma glutamyl transferase in domestic animals. Vet. Res. Commun., v.6, p.77-90, 1983.

CAMPOS, H. Estatística experimental não paramétrica. Piracicaba: ESALQ, 1979. 332p.

COSTA NETO, P.L.O. Estatística. 2.ed. São Paulo: Edgard Blücher, 2002. 266p.

DIAL, S.M. Clinicopathologic evaluation of the liver. Vet. Clin. N. Am: Small Anim. Pract., v.25, p.257-273, 1995.

FERRER, L. Leishmaniasis In: KIRK, R.W.; BONAGURE, J.D. (Eds). Current veterinary therapy. Philadelphia: W.B. Saunders, 1992. p.266-270.

HAG, I.A.E.; HASHIM, F.A.; TOUM, I.A.E. et al. Liver morphology and function in visceral leishmaniasis (Kala-azar). J. Clin. Pathol., v.47, p.547-551, 1994.

KELLER, P. Enzyme activities in the dog: tissue analyses, plasma values, and intracellular distribution. Am. J. Vet. Res., v.42, p.575-582, 1981.

LUVIZOTTO, M.C.R. Alterações patológicas em animais naturalmente infectados. In: FÓRUM SOBRE LEISHMANIOSE VISCERAL CANINA, 1., 2006, Jaboticabal. Anais... Jaboticabal, FCAV/UNESP, 1974. p.15-22.

MATTOS JR., D.G.; PINHEIRO, J.M.; MENEZES, R.C. et al. Aspectos clínicos e de laboratório de cães soropositivos para leishmaniose. Arq. Bras. Med. Vet. Zootec., v.56, p.119-122, 2004.

NOLI, C. Leishmaniosis canina. Waltham Focus, v.9, p.16-24, 1999.

SHULL, R.M.; HORNBUCKLE,W. Diagnostic use of serum $\gamma$ glutamyl transferase in canine liver disease. Am. J. Vet. Res., v.40, p.13211324, 1979.

SUTHERLAND, R.J.; Biochemical evalution of the hepatobiliary system in dogs and cats. Vet. Clin. N. Am.: Small Anim. Pract., v.19, p.899927, 1989.

TAFURI, W.L.; TAFURI, W.L.; BARBOSA, A.J.A. et al. Histopathology and immunocytochemical study of type 3 and type 4 complement receptors in the liver and spleen of dogs naturally and experimentally infected with Leishmania (Leishmania) chagasi. Rev. Inst. Med. Trop., v.38, p.81-89, 1996.

TRYPHONAS, L.; ZAWIDZKA， Z.; BERNARD, M.A. et al. Visceral leishmaniasis in a dog: clinical, hematological and pathological observations. Can. J. Comp. Med., v.41, p.1-12, 1977.

VALLADARES, J.E.; RIERA, C.; PASTOR, J. et al. Hepatobiliar and renal failure in a dog experimentally infected with Leishmania infantum. Vet. Rec., v.141, p.574-575, 1997.

WILLIS, S.E.; JACKSON, M.L.; MERIC, S.M. et al. Whole blood platelet aggregation in dogs with liver disease. Am. J. Vet. Res., v.50, p.18931990, 1989. 